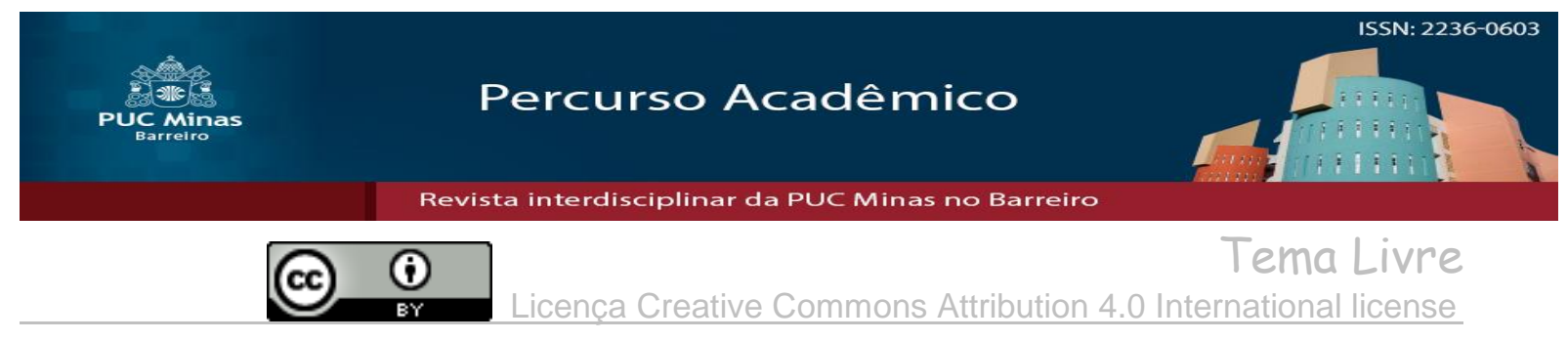

\title{
Comparativo entre custos operacionais na potabilização de águas superficiais e subterrâneas em pequenas cidades
}

\section{Comparison between operational costs for the purification of surface and groundwater in small towns}

\author{
Paulo Filho Machado Ribeiro ${ }^{1}$ \\ Marília Carvalho de Melo ${ }^{2}$
}

\begin{abstract}
RESUMO
A água constitui, um elemento de grande necessidade à manutenção da vida, além de ser considerada o composto mais abundante em nosso planeta, ocupando aproximadamente $70 \%$ da superfície do mesmo. No entanto, $97 \%$ desta água é salgada e, portanto, imprópria ou com grande dificuldade de torna-la própria para o consumo humano. Menos de 3\% da água do planeta é doce, das quais 2,5\% está em geleiras e os outros $0,5 \%$ de água restantes no mundo em águas superficiais ou subterrâneas. Atualmente os mananciais subterrâneos, devido a qualidade da água bruta que geralmente apresenta baixa variabilidade qualitativa, têm se mostrado uma boa alternativa como fonte de água potável, principalmente em comunidades que possuem indisponibilidade ou que precisam incrementar seus sistemas de tratamento, normalmente exclusivamente superficiais, com novas fontes de águas provenientes de mananciais subterrâneos. Sendo assim, este trabalho irá apresentar resultados obtidos a partir de uma análise econômica dos custos com tratamento de água potável para cidades localizadas dentro do território do estado de Minas Gerais e com população menor que 5.000 habitantes. As análises foram realizadas comparando os custos mensais de mão de obra e eletricidade em sistemas de tratamento da água com tipos distintos de mananciais, superficial e subterrâneo.
\end{abstract}

Palavras chave - Poços de água, águas superficiais, águas subterrâneas, custos, tratamento de água.

\section{ABSTRACT}

\footnotetext{
Artigo recebido em 17 de outubro de 2019 e aprovado em 18 de março de 2020

${ }^{1}$ Especialização em Engenharia Sanitária e Ambiental pela Pontifícia Universidade Católica de Minas Gerais (PUCMG) e graduação em Engenharia Ambiental pela FUMEC. Atualmente é Especialista em Manejo de Rejeito da Fundação Renova. Brasil. E-mail: paulosmribeiro@gmail.com

2 Doutorado em Recursos Hídricos pelo Programa de Engenharia Civil pela Universidade Federal do Rio de Janeiro (COPPE/UFRJ), Mestrado em Saneamento, Meio Ambiente e Recursos Hídricos pela Universidade Federal de Minas Gerais (UFMG), Especialização em Gestão com ênfase em negócios pela Fundação Dom Cabral Possui e graduação em Engenharia civil pela UFMG. Atualmente é professora e coordenadora do mestrado da Universidade Vale do Rio Verde de Três Corações, professor da Escola de Engenharia Kennedy e diretora geral do Instituto Mineiro de Gestão das Águas. Brasil. E-mail: mariliacmelo@yahoo.com.br
} 
Water is an element of great need for the maintenance of life, and is also considered the most abundant compound on our planet, occupying approximately $70 \%$ of its surface. However, $97 \%$ of this water is salty and therefore improper or with great difficulty to make it potable for human consumption. Less than 3 percent of the world's water is fresh, 2.5 percent of which is in glaciers, and the 0.5 percent remaining of the world's water, located in surface or underground aquifers. Nowadays, underground springs, due to the quality of raw water that usually low qualitative variability, have been considerate as a good alternative as a source of drinking water, especially in communities that have unavailability or need to increase their current treatment systems, usually only superficial, as new sources of raw water. Thus, this paper will present results obtained from an economic analysis of drinking water treatment costs for cities located within the territory of the state of Minas Gerais and with a population of less than 5,000 inhabitants. Analyzes were performed by comparing monthly labor and electricity costs in water treatment systems with different types of springs, surface and underground.

Keywords - Water wells, surface water, groundwater, costs, water treatment.

\section{INTRODUÇÃO}

A água ocupa aproximadamente $75 \%$ da superfície da Terra e integra aproximadamente dois terços do corpo humano, atingindo até $98 \%$ para certos animais aquáticos, além de ser o solvente universal da maioria das substâncias, modificando-as e modificando-se em função destas (LIBÂNIO, 2008). Utilizada para o consumo humano e para as atividades socioeconômicas, é retirada de rios, lagos, represas e aquíferos, tendo influência direta sobre a saúde, a qualidade de vida e o desenvolvimento das populações (SCURACCHIO, 2010).

Conforme informações da Agencia Nacional de Águas (ANA) estima-se que o Brasil possua cerca de $12 \%$ da disponibilidade de água doce do planeta, porém a distribuição natural desse recurso é desequilibrada. A região Norte, por exemplo, concentra aproximadamente $80 \%$ da quantidade de água disponível, mas representa apenas $5 \%$ da população brasileira. Já em contrapartida, as regiões litorâneas possuem mais de $45 \%$ da população, porém, menos de 3\% dos recursos hídricos do país (Brasil, 2010).

Segundo o Departamento de Engenharia de Saúde Pública da Fundação Nacional de Saneamento (FUNASA,2010), no Brasil, no ano de 2010 cerca de 29,9 milhões de pessoas residem em localidades rurais totalizando, aproximadamente, 8,1 milhões de domicílios, dos quais cerca de 2,8 milhões, ou 35,4\%, apresentam algum déficit no serviço de abastecimento de água potável. 
Dados do Instituto Brasileiro de Geografia e Estatística (IBGE) para o Estado de Minas Gerais, considerando o ano base de 2008, mostram que 758 dos 853 municípios apresentavam um sistema de distribuição completo de água tratada, ou seja, aproximadamente $11 \%$ dos municípios ainda apresentavam um sistema deficitário ou realizavam a distribuição de água sem tratamento adequado, não atendendo as normativas mínimas de potabilidade requeridas pelo Ministério da Saúde e colocando a população em risco (Brasil,2008). Esta situação demonstra a necessidade de se avaliar fontes alternativas para o abastecimento público nas cidades de Minas Gerais.

Em Minas Gerais, o Atlas Brasil - Abastecimento Urbano de águas, da ANA, mostra que, no ano de 2015, 169 municípios eram abastecidos por água subterrânea e outros 35 possuíam sistema misto de abastecimento, ou seja, aproximadamente $20 \%$ utilizam água subterrânea exclusivamente, $4 \%$ sistemas mistos, enquanto $76 \%$ dos municípios utilizam água superficial para realizar o abastecimento de suas áreas urbanas (Brasil,2015). O mesmo estuda aponta que no ano de 2015, 423 municípios precisariam passar por algum tipo de expansão no sistema de tratamento para atender ou se adequarem as necessidades futura da população.

A água subterrânea é considerada mundialmente uma fonte imprescindível de abastecimento para o consumo humano, principalmente para populações que não têm acesso à rede pública de abastecimento ou mesmo para aqueles que, tendo acesso, têm o fornecimento irregular (Freitas, 2001). Adicionalmente as águas subterrâneas, em função da proteção natural do solo e rochas nas quais se encontram confinadas, são menos susceptíveis a contaminações que as águas superficiais. Esta característica pode possibilitar a redução dos custos com o tratamento. Corrobora-se a afirmativa o fato de que o custo de bombeamento da água, que em alguns casos, possa ser inferior ao custo do tratamento das águas superficiais (Manoel Filho, 2004).

Os requisitos de qualidade para provimento de água potável estão estabelecidos na Portaria de Consolidação do Ministério da Saúde $N^{o} 5$ de 2017. O Anexo XX da referida norma trata da qualidade da água para consumo humano e o seu padrão de potabilidade (Brasil, 2011). Deve-se ressaltar que o custo de tratamento para que seja atingido o padrão de potabilidade tem relação direta com a qualidade da água bruta disponível. Neste sentido, as águas subterrâneas, como já exposto, possuem, via de regra, melhores condições que as águas superficiais. 
Assim os sistemas de captação de água subterrânea têm ganhado maior visibilidade, especialmente para sistemas menores ou soluções individualizadas ou abastecimento em áreas rurais, se mostrado cada vez mais uma alternativa plausível às concessionárias que hoje buscam meios mais efetivos para tratamento e distribuição das águas. Desta forma, justifica-se a avaliação de custos associados à operação dos sistemas de água considerado a utilização de mananciais subterrâneos ou superficiais.

Neste contexto, este trabalho tem como objetivo estabelecer uma comparação dos custos de operação de um sistema tratamento de água potável utilizando mananciais de água superficial e subterrâneo para cidades com menos de 5.000 habitantes no Estado de Minas Gerais.

\section{METODOLOGIA}

\subsection{Definição da amostra populacional}

Durante o processo de levantamento dos dados referente ao número de habitantes por municípios em Minas Gerais, foi possível verificar que aproximadamente 92\% (786) dos municípios mineiros apresentam população total menor que 50.000 habitantes, conforme Figura 01 (IBGE,2010). Estas cidades seriam classificadas como pequenos, segundo o IBGE. Adicionalmente, no estado de Minas Gerais, no ano de 2010, demonstram uma população total de 19.597 .330 habitantes dos quais, cerca de $85 \%$ (16.715.216) em área urbana (IBGE,2010).

Figura 01: Distribuição de municípios em Minas Gerais por número de habitantes

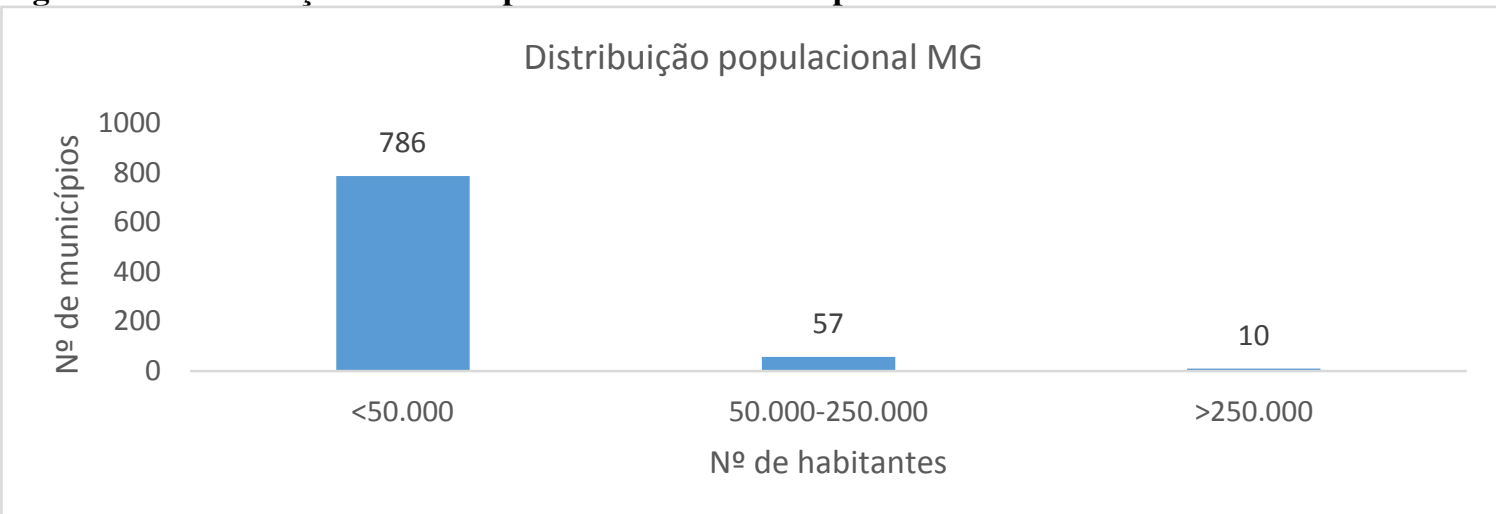

Fonte: IBGE

Da avaliação dos municípios considerados pequenos, foi possível verificar que $57 \%$ (490) dos municípios apresentam uma população inferior a 10.000 habitantes e $28 \%$ (240) apresentam menos que 5.000 habitantes (Figura 02). 
Figura 02: Número de Cidade com menos de 50 mil habitantes em Minas Gerais

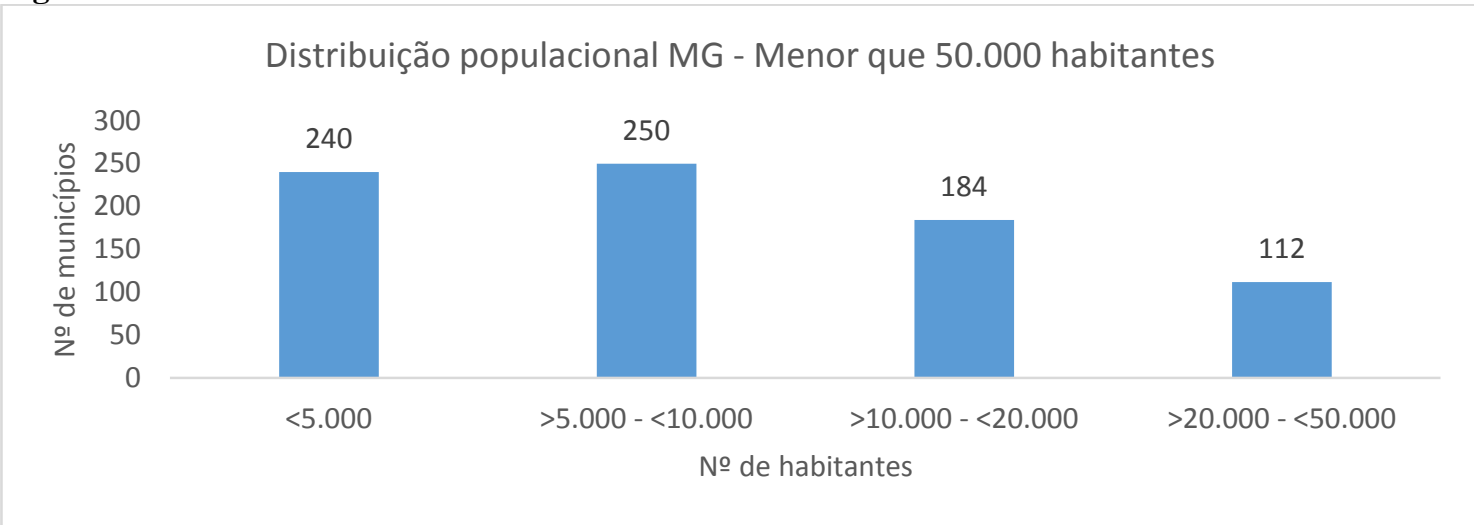

Fonte: IBGE

Considerando a tendência do uso de água subterrânea como uma alternativa viável para municípios com populações pequenas, foi estabelecido, para fins de cálculo de custo de operação, a adoção de uma cidade hipotética com 5.000 habitantes, desta forma com um potencial de beneficiar aproximadamente 800.000 habitantes em Minas Gerais.

Segundo dados do Sistema Nacional de Informações Sobre o Saneamento (SNIS) em 2010 o consumo médio per capita de água potável no estado de Minas Gerais foi de 154,07 litros.habitante ${ }^{-1} \cdot \mathrm{dia}^{-1}$, ou seja, aproximadamente $40 \%$ maior que o recomendado pela Organização Mundial da Saúde (OMS), que é de 110 litros.habitante ${ }^{-1} \cdot$ dia $^{-1}$.

Adotou-se, portanto, para avaliação da vazão total necessária, um consumo per capita de 154,07 litros.habitante ${ }^{-1} \cdot$ dia $^{-1}$.

\subsection{Estimativa da produção de poços tubulares (água bruta)}

Para o dimensionamento das vazões de produção de poços tubulares no estado de Minas Gerais foi utilizada uma referência do Plano Estadual de Recursos Hídrico de Minas Gerais (IGAM, 2010). O plano apresenta dados referentes a 758 poços inventariados em MG, onde 609 foram considerados produtivos, ou seja, forneceram vazão em quantidade compatível. Enquanto 149 resultaram em secos ou tiveram vazão insuficiente (vazão inferior a 0,02 1/s), sendo assim, 19,65\% das perfurações não atenderam à expectativa de produção de água.

Dos 609 poços produtivos, a vazão variou entre 0,03 e 40,00 1.s ${ }^{-1}$, tendo como média o valor de $1,921 . \mathrm{s}^{-1}$. Em $68 \%$ dos poços a vazão se situa na faixa entre 0,1 e 2 1/s, em 
$20 \%$ deles a vazão está compreendida entre 2 e $41 . \mathrm{s}^{-1}$, e, em apenas $10 \%$ a produção é superior a $4,21 . \mathrm{s}^{-1}$.

Para o dimensionamento do manancial subterrâneo nesse estudo, considerou-se o dado de vazão média de $1,921 . \mathrm{s}^{-1}$ ou por aproximação, $7.000 \mathrm{~L} \cdot \mathrm{h}^{-1}$ por poço, confome apresentado do Plano Estadual de Recursos Hídricos de Minas Gerais (IGAM, 2010).

Desta forma, para atendimento da vazão de consumo total (770.350 1.dia ${ }^{-1}$ ou 32.098 1.h ${ }^{1}$.), seriam necessários a operação de no mínimo 6 poços. Considerou-se a Instrução técnica DPO nº 10, de 30/05/2017 da Secretaria de Estado de Saneamento e Recursos Hídricos de São Paulo, para limitação do tempo máximo de bombeamento de 20h.dia ${ }^{-1}$ por poço, para garantia da recuperação do aquífero e manutenção das vazões (SABESP,2017).

Assim, foi estabelecido a quantidade de poços necessários para abastecer a população proposta neste trabalho (Equação 1)

\section{Equação 01:}

$V p d=V p \times T b=7.000 \frac{l}{h} \times 20 \frac{h}{\text { dia }}=140.000 \frac{l}{\text { dia }}$

$P t=\frac{V c}{V p d}=\frac{770.350 \frac{l}{d i a}}{140.000 \frac{l}{d i a}}=5,5$ poços

Sendo:

$\mathrm{Vp}=$ Vazão horária de um poço

Vpd = Vazão diária de um poço

$\mathrm{Vc}=$ Vazão de consumo total

$\mathrm{Tb}=$ Tempo máximo de bombeamento do poço

$\mathrm{Pt}=$ Número de poços total

Desta forma serão adotados 6 poços, totalizando uma vazão 840.000 1.dia $^{-1}$, suficiente para atender a demanda da população.

A Figura 3 apresenta um fluxograma simplificado de um sistema típico de abastecimento de água potável cujo manancial é subterrâneo. 
Figura 03: Fluxograma do sistema de captação e adução das águas subterrâneas

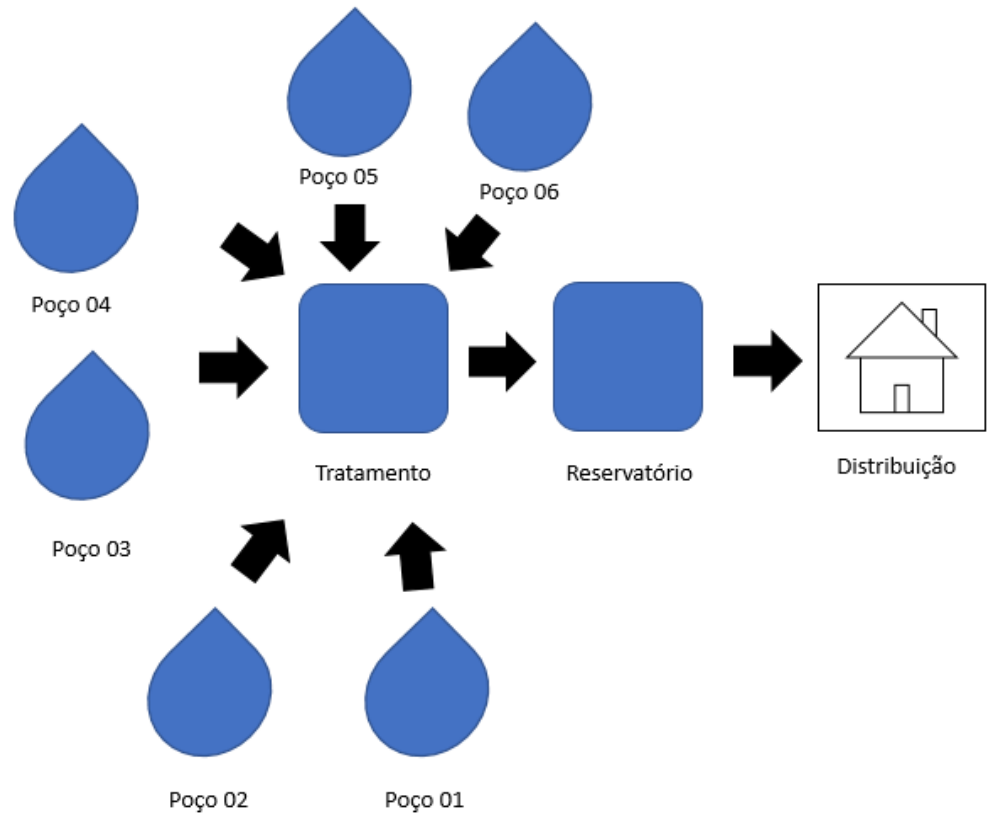

Fonte: Autor

\subsection{Estimativas da produção de da fonte superficial (água bruta)}

\subsection{1 Água Superficial}

Para águas superficiais, para atendimento da vazão de água bruta, foi estabelecido de forma arbitrária um ponto único com a vazão de $32.0981 . \mathrm{h}^{-1}$ para captação. O fluxograma simplificado de um sistema de abastecimento com manancial superficial está demonstrado na Figura 4.

Figura 04: Fluxograma do sistema de captação e adução das águas superficiais

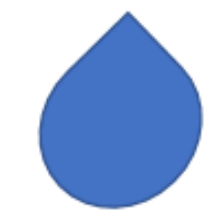

Água superficial

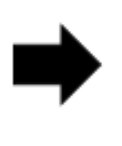

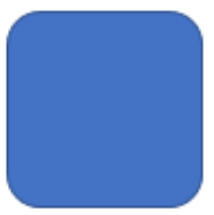

Tratamento

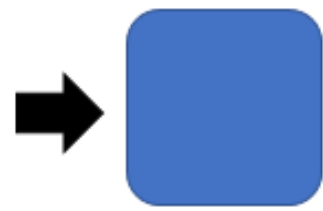

Reservatório

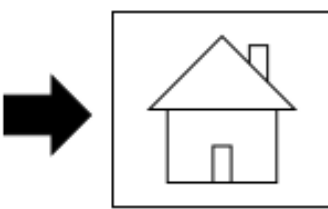

Distribuição

Fonte: Autor 


\subsection{Fluxograma dos processos tratamento}

Segundo o Sistema Estadual de Informações sobre o Saneamento (SEIS), o tipo de manancial em que é feita a captação de água é um dos componentes que determina o tipo de tratamento que deve ser adotado para uma oferta de água de qualidade. A água de lençóis subterrâneos, sobretudo dos muito profundos, geralmente apresenta boa qualidade e composição constante num mesmo lençol, sendo menos vulnerável à poluição que a água superficial ou a água subterrânea de camadas menos profundas (FJP,2014).

\subsection{1 Água Superficial}

A Deliberação Normativa (DN) Conjunta do Conselho de Política Ambiental (COPAM) e Conselho Estadual de Recursos Hídricos (CERH) 01 de 2008, estabelece o enquadramento dos corpos de água segundo os usos preponderante e define requisitos de qualidade para cada uma das Classes de enquadramento.

Considerando que a maior parte dos cursos d'água de Minas Gerais são classificados como Classe 2, conforme DN COPAM/ CERH 01/08 (SEMAD,2008). A mesma norma estabelece que corpos de água superficiais enquadrado como Classe 2 podem ser utilizadas para abastecimento humano após tratamento convencional. Portanto será considerado a operação de tal sistema para levantamento de custos com captação superficial.

Segundo a Companhia de Saneamento de Minas Gerais (COPASA), um sistema convencional é composto de captação com tratamento desarenação, oxidação, coagulação, floculação, decantação, filtração, desinfecção, correção do pH e fluoretação, conforme Figura 05. 
Figura 05: Fluxograma do sistema de distribuição (água superficial)

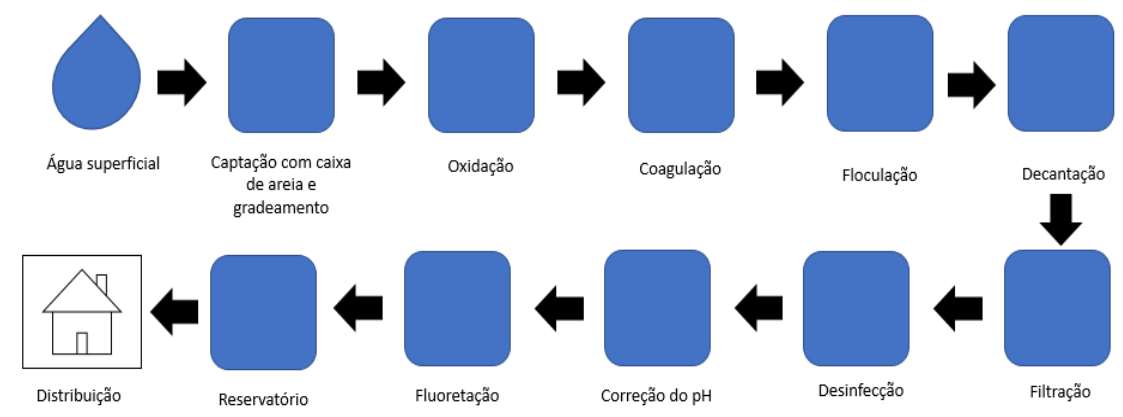

Fonte: COPASA

\subsection{2 Água Subterrânea}

Conforme informações da COPASA, a água captada por meio de poços profundos, na maioria das vezes não precisa passar pelo tratamento convencional, bastando apenas a desinfecção simples com cloro. Isso ocorre porque normalmente não apresenta turbidez fora dos parâmetros estabelecidos pela Portaria Consolidada nº5/2017, o valor máximo permitido para a turbidez de água potável é de 5,0 NTU, eliminando as outras fases que seriam necessárias ao tratamento das águas superficiais de rios de Classe 2.

Figura 06: Fluxograma do sistema de distribuição (água subterrânea)

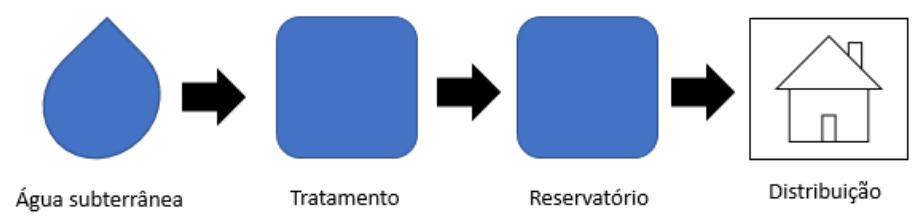

Fonte: COPASA

\subsection{Requisitos de qualidade da água potável e monitoramento}

Ministério da Saúde, através da PORTARIA DE CONSOLIDAÇÃO No 5 - Anexo XX de 2017, realizou a consolidação das normas sobre as ações e os serviços de saúde do Sistema Único de Saúde referentes ao controle e da vigilância da qualidade da água para consumo humano e seu padrão de potabilidade.

A Portaria de Consolidação estabelece procedimentos de controle e de vigilância da qualidade da água para consumo humano e seu padrão de potabilidade em águas 
destinadas ao consumo humano proveniente de sistema e/ou solução alternativa de abastecimento de água.

Para padronização neste trabalho, o plano de monitoramento da água potável considerará os parâmetros que requerem as maiores frequências de coletas de amostras, sendo então listados os seguintes parâmetros para água tratada, conforme Tabela 01 .

Tabela 01: Parâmetros de monitoramento da qualidade da água tratada (Portaria Consolidada n5)

\begin{tabular}{c|c|c}
\hline \multirow{2}{*}{ Parâmetros } & \multicolumn{2}{|c}{ Periodicidade de amostra } \\
\cline { 2 - 3 } & Superficial & Subterrâneo \\
\hline Cor & a cada 2 horas & Semanal \\
\hline Turbidez, Cloro Residual Livre, Cloraminas, Dióxido de Cloro & a cada 2 horas & 2 vezes por semana \\
\hline pH e fluoreto & a cada 2 horas & 2 vezes por semana \\
\hline
\end{tabular}

Fonte: Ministério da Saúde.

\subsection{Custos de operação do sistema de tratamento}

\subsubsection{Energia elétrica}

Segundo Perroni (Perroni,2004) em estudo realizado para a cidade de Araraquara/SP, avaliou os custos energéticos com o tratamento da água comparando os modelos de tratamento das águas superficiais e subterrânea deste município. Os custos com o tratamento da água apresentaram valores muito similares, na ordem de R \$ 0,204 para o metro cúbico de água subterrânea e R 0,247 para o metro cúbico de água superficial.

\subsubsection{Equipe e mão de obra}

Levando em consideração as premissas metodológicas deste estudo, para o tratamento da água superficial foi estabelecida uma equipe necessária para a operação de um sistema convencional de tratamento de água, com uma operação continuada de 24 h.dia ${ }^{-}$ 1 . Este dimensionamento de equipe se dá devido a variabilidade da qualidade da água bruta do sistema superficial ao longo do dia e a necessidade de atendimento ao plano de monitoramento estabelecido pela Portaria de Consolidação $n^{\circ} 5$ do Ministério da Saúde (MS,2017). A variação da condição de qualidade das águas ao longo do dia não é uma característica de mananciais subterrâneos, portanto aplica-se um tratamento com cloração para desinfecção, cuja operação requer um acompanhamento mais simplificado, em horário administrativo e em dias úteis. 
Para o dimensionamento dos custos com operação dos sistemas de tratamento das águas e dimensionamento da equipe, tanto para o manancial superficial (tratamento convencional) quanto para o manancial subterrâneo (cloração), serão utilizados os salários e descritivos de cargos do ANEXO I do EDITAL 017/2018 da COPASA (FUMARC,2017).

Para operação do sistema convencional foi estabelecida uma equipe de 4 (quatro) operadores de Estação de Tratamento de Água (ETA) que também serão responsáveis pelo monitoramento dos parâmetros da qualidade da água. A jornada de trabalho, para fins de cálculo dos custos, foi definida por rodízio em 4 turnos de 12 horas (12x36), que conforme previsto na Súmula $\mathrm{n}^{\circ} 444$ do Tribunal Superior do Trabalho (TST) somente será válida mediante acordo ou convenção coletiva do trabalho. Segundo o TST, esta modalidade de rodizio de turnos é muito frequente em empresas que precisam manter uma operação continua e com duração de $24 \mathrm{~h} \cdot \operatorname{dia}^{-1}$ (TST,2017). Além de 1 (um) mecânico de manutenção de equipamentos que realizará a manutenção preventiva e corretiva dos equipamentos, e de 1 (um) auxiliar de serviços que ficará responsável pela limpeza dos filtros, calhas e caixas de areia, dando o suporte também na recepção e preparação dos insumos químicos a serem utilizados no processo. Ambos prestarão serviços durante horário administrativo e em dias úteis da semana.

Para operação do sistema simples de dosagem de cloro, estabeleceu-se uma equipe de 1 (um) operador de Estação de Tratamento de Água (ETA) que também será responsável pela realização do monitoramento dos parâmetros da qualidade da água, além de 1 (um) mecânico de manutenção de equipamentos que realizará a manutenção preventiva e corretiva dos equipamentos. Ambos prestarão serviços durante horário administrativo e em dias úteis.

Para valoração dos custos com a equipe foram contabilizados apenas os pagamentos de salários brutos de cada categoria, e os seguintes encargos trabalhistas: INSS, FGTS, férias e décimo terceiro, não considerando, portanto, outros encargos ou benefícios (Tabela 2). 
Comparativo entre custos operacionais na potabilização de águas superficiais e subterrâneas em pequenas cidades

Tabela 02: Salários e encargos trabalhistas

\begin{tabular}{|c|c|c|c|c|c|c|}
\hline Parâmetros & $\begin{array}{c}\text { Salário Bruto } \\
\text { anual }(\mathrm{R} \$)\end{array}$ & $\begin{array}{l}\text { INSS } \\
(8 \%)\end{array}$ & $\begin{array}{r}\text { FGTS } \\
(8 \%)\end{array}$ & $\begin{array}{l}\text { Férias } \\
(\mathrm{R} \$)\end{array}$ & $\begin{array}{c}\text { Décimo } \\
\text { terceiro } \\
(\mathrm{R} \$)\end{array}$ & $\begin{array}{l}\text { Gasto Mensal final } \\
(\mathrm{R} \$)\end{array}$ \\
\hline Operador de ETA & $20.268,72$ & \multirow{3}{*}{$8 \%$} & \multirow{3}{*}{$8 \%$} & 563,02 & $1.689,06$ & $2.169,50$ \\
\hline Auxiliar de serviço & $16.575,72$ & & & 460,44 & $1.381,31$ & $1.774,22$ \\
\hline Mecânico de manutenção & $18.725,16$ & & & 520,14 & $1.560,43$ & $2.004,29$ \\
\hline
\end{tabular}

Fonte: COPASA.

\subsubsection{Premissas Consolidadas}

A Tabela 03 apresenta a consolidação dos requisitos metodológicos adotados no presente estudo para a avaliação comparativa dos custos com operação de sistemas de abastecimento com manancial superficial ou subterrâneo.

Tabela 03: Premissas metodológicas

\begin{tabular}{|c|c|c|}
\hline Parâmetros & \multicolumn{2}{|c|}{ Dados } \\
\hline População total & \multicolumn{2}{|c|}{5.000 habitantes } \\
\hline Parâmetros de qualidade da água & \multicolumn{2}{|c|}{$\begin{array}{c}\text { Cor, Turbidez, Cloro Residual Livre, Cloraminas, } \\
\text { Dióxido de Cloro, } \mathrm{pH} \text { e fluoreto }\end{array}$} \\
\hline Consumo médio & \multicolumn{2}{|c|}{ 154,07 L.hab ${ }^{-1} \cdot$ dia $^{-1}$} \\
\hline \multirow{2}{*}{ Vazão média por ponto de captação } & Superficial & $7.0001 . h^{-1}$ \\
\hline & Subterrânea & 32.098 1.h-1 \\
\hline Tempo de operação diário de um poço & \multicolumn{2}{|c|}{20 h.dia ${ }^{-1}$} \\
\hline Consumo total & \multicolumn{2}{|c|}{$23.110 \mathrm{~m}^{3} \cdot \mathrm{mês}^{-1} / 770.3501 . \mathrm{dia}^{-1} / 32.0981 . \mathrm{h}^{-1}$} \\
\hline \multirow{2}{*}{ Número de pontos de captação } & Superficial & 1 ponto \\
\hline & Subterrânea & 5 pontos \\
\hline \multirow{2}{*}{ Custo energia elétrica } & Superficial & $0,247 \mathrm{R} \$ . \mathrm{m}^{3}$ \\
\hline & Subterrânea & $0,204 \mathrm{R} \$ . \mathrm{m}^{3} \mid$ \\
\hline \multirow[t]{2}{*}{ Número de funcionários } & Superficial & $\begin{array}{c}4 \text { operadores de ETA } \\
1 \text { mecânico de } \\
1 \text { assistente de operação }\end{array}$ \\
\hline & Subterrânea & $\begin{array}{l}1 \text { operadores de ETA } \\
1 \text { mecânico }\end{array}$ \\
\hline
\end{tabular}

Fonte: Ministério da Saúde, COPASA e Perroni. 


\section{Resultados e discussão}

Considerando as premissas apresentadas na metodologia foi possível realizar as comparações e verificar o custo total com o tratamento de água potável conforme os resultados apresentados.

\subsection{Vazões de consumo}

Considerando a referência para o consumo per capita e o número total de habitantes, a vazão demandada para abastecer a área urbana de um município de 5.000 habitantes será de 770.350 1.dia ${ }^{-1}$ (Equação 02).

\section{Equação 02}

$V c=C p \times P$

$V c=154,07 \frac{l}{\text { habitantes } x \text { dia }} \times 5.000$ habitantes $=770.350 \frac{l}{\text { dia }}$

Sendo:

$\mathrm{Vc}=$ Vazão de consumo total

$\mathrm{Cp}=$ Consumo per capta

$\mathrm{P}=$ População

$\mathrm{Vc}=$ Vazão de consumo total

\subsection{Estimativas de custos de operação}

Escrever uma breve contextualização aqui!

\subsubsection{Custo - Energia elétrica}

Considerando a referência para os custos com eletricidade por $\mathrm{m}^{3}$ de água tratado e o volume total de água consumida em um mês, para uma população considerada pequena, o custo unitário por metro cúbico de cada manancial, apresentaram uma diferença de $17 \%$.

$C f e=\operatorname{Cesp} \times V c$

Cfesup $=0,247 \frac{R \$}{m^{3}} \times 23.110 \frac{m^{3}}{m \hat{e ̂} s}=5.708,17 \frac{R \$}{m e s}$

Cfesub $=0,204 \frac{R \$}{m^{3}} \times 23.110 \frac{m^{3}}{m \hat{e ̂} s}=4.714,44 \frac{R \$}{m \hat{e ̂} s}$

Sendo:

$\mathrm{Vc}=$ Vazão de consumo total 
Cesp $=$ Custo especifico de tratamento

Cfesub $=$ Custo final com eletricidade (manancial subterrâneo)

Cfesup= Custo final com eletricidade (manancial subterrâneo)

\subsection{Custos - Equipe e mão de obra}

A necessidade de operação assistida, durante 24 h.dia-1, de um sistema convencional de tratamento de água com captação em manancial superficial, onerou em aproximadamente $200 \%$ os custos quando comparado ao sistema simplificado com captação subterrâneo.

A contratação de 4(quatro) operadores responsáveis pela operação e monitoramento continuo do sistema de tratamento de água superficial faz com que, somente nesta categoria, os custos fiquem $300 \%$ mais elevados que os custos com das águas subterrâneas. Além disso, é acrescido o custo com um assistente de operação, responsável principalmente pela limpeza e manutenção do sistema primário de tratamento da água, gradeamento e caixa, equipamentos que não estão presente no sistema simplificado.

$$
\begin{aligned}
& C f m=(N c \times C o)+(N c \times C a)+(N c \times C m) \\
& C f m s u p=\left(4 \times 2.169,50 \frac{R \$}{m \hat{\mathrm{e} s}}\right)+\left(1 \times 1.774,22 \frac{R \$}{m \hat{\mathrm{e} s}}\right)+\left(1 \times 2.004,29 \frac{R \$}{m \mathrm{ês}}\right) \\
& =12.462,51 \frac{R \$}{m \hat{e} s} \\
& C f m s u b=\left(1 \times 2.169,50 \frac{R \$}{m \hat{\mathrm{e} s}}\right)+\left(1 \times 2.004,29 \frac{R \$}{m \mathrm{ês}}\right)=4.174,79 \frac{R \$}{m \mathrm{ê} s}
\end{aligned}
$$

Sendo:

$\mathrm{Co}=$ Custo mensal do operador de ETA

$\mathrm{Ca}=$ Custo mensal do auxiliar de serviço

$\mathrm{Cm}=$ Custo mensal do Mecânico de manutenção

$\mathrm{Nc}=$ Número de colaboradores

Cfmsup = Custo final da mão de obra (manancial superficial)

Cfmsub = Custo final da mão de obra (manancial subterrâneo)

\subsubsection{Custo Total}

O custo com mão de obra, no caso da captação superficial foi de $68 \%$ do custo final com o tratamento, enquanto no caso do manancial subterrâneo foi de $47 \%$. 


$$
\begin{aligned}
& C t s u p=C f \text { esup }+C f \text { msup }=5.708,17 \frac{R \$}{m \hat{\mathrm{e} s}}+12.462,51 \frac{R \$}{m \mathrm{e} s}=18.170,68 \frac{R \$}{m \mathrm{e} s} \\
& C t \text { sub }=C f \text { esub }+C f m s u b=4.714,44 \frac{R \$}{m \hat{\mathrm{e} s}}+4.174,79 \frac{R \$}{m \hat{\mathrm{e}} s}=8.889,23 \frac{R \$}{m \hat{\mathrm{e}} s}
\end{aligned}
$$

Sendo:

Ctsup $=$ Custo total (manancial superficial)

Ctsup = Custo total (manancial subterrâneo)

Cfmsup = Custo final da mão de obra (manancial superficial)

Cfmsub = Custo final da mão de obra (manancial subterrâneo)

$\mathrm{Cfesub}=$ Custo total com eletricidade (manancial subterrâneo)

Cfesup $=$ Custo total com eletricidade (manancial subterrâneo)

A Tabela 04 apresenta a consolidação final dos custos levantados com os dois tipos de captação e tratamento da água.

\begin{tabular}{|c|c|c|}
\hline \multicolumn{3}{|c|}{ Elétrico } \\
\hline Tipo de manancial & & Custo mensal (R\$) \\
\hline Superficial & & $5.708,17$ \\
\hline Subterrâneo & & $4.714,44$ \\
\hline \multicolumn{3}{|c|}{ Mão de obra } \\
\hline Cargo & Manancial Superficial & Manancial Subterrâneo \\
\hline Operador de ETA & 5 & 1 \\
\hline Auxiliar de serviço & 1 & - \\
\hline Mecânico de manutenção & 1 & \begin{tabular}{l|r} 
& 1 \\
\end{tabular} \\
\hline \multicolumn{2}{|l|}{ Tipo de manancial } & Custo mensal (RS) \\
\hline Superficial & & $12.462,51$ \\
\hline Subterrâneo & & $4.173,79$ \\
\hline \multicolumn{3}{|c|}{ Custo total } \\
\hline \multirow{2}{*}{$\begin{array}{c}\text { Tipo de manancial } \\
\text { Superficial }\end{array}$} & & Custo mensal (R\$) \\
\hline & & $18.170,68$ \\
\hline $\begin{array}{c}\text { Superficial } \\
\text { Subterrâneo }\end{array}$ & & $8.889,23$ \\
\hline
\end{tabular}

Tabela 04: Custos Totais de operação dos Sistemas

Fonte: Autor.

O Quadro 04 mostra os custos específicos e total com o tratamento das águas dos dois mananciais estudados, sendo possível verificar uma maior dependência da mão de obra na operação do sistema superficial.

\section{CONCLUSÃO}

O propósito deste trabalho foi analisar as duas principais modalidades de captações, comparando os custos envolvidos para o tratamento da água a ser distribuída para o consumo humano em pequenas cidades do estado de Minas Gerais. 
O grande impacto nos custos operacionais refere-se aos gastos com mão de obra, que no caso do manancial superficial foi $200 \%$ maior quando comparado ao manancial subterrâneo. Sendo assim, foi possível demonstrar que o custos totais com o sistema de tratamento de água de um manancial subterrâneo, se mostrou menor quando comparado ao manancial superficial em aproximadamente 104\%, ou seja, sua operação é economicamente viável desde que respeitadas as premissas apresentadas. Portanto, para pequenas populações e considerando a produtividades dos poços, a captação em mananciais subterrâneos se apresenta como uma opção com um custo operacional melhor quando comparado aos mananciais de águas superficiais.

\section{REFERÊNCIAS}

LIBÂNIO, M. Fundamentos de qualidades e tratamentos de água. 2 ed. Campinas: Editora Átomo, 2008.

SCURACCHIO, P. A. Qualidade da Água Utilizada para Consumo em Escolas no Município de São Carlos - SP.Dissertação (Mestrado). Araraquara, 2010.

ANA, AGENCIA NACIONAL DE ÁGUAS - Atlas Brasil - Abastecimento Urbano de água; Disponível em: 〈http://atlas.ana.gov.br/Atlas/forms/ResultadosEstado.aspx> Acesso em: 20, agosto, 2019.

IBGE, INSTITUTO BRASILEIRO DE GEOGRAFIA E ESTATÍSTICA - Instituto Diretoria de Pesquisas, Coordenação de População e Indicadores Sociais, Pesquisa Nacional de Saneamento Básico 2008. BRASIL.

FJP, FUNDAÇÃO JOÃO PINHEIRO - Sistema Estadual de Informações Sobre o Saneamento, Saneamento Básico de Minas Gerais, 2014. Minas Gerais.

BRASIL, Ministério da Saúde. PORTARIA DE CONSOLIDAÇÃo No 5 ANEXO XX., DE 28 DE SETEMBRO DE 2017. Brasília, 2017.

COPASA, COMPANHIA DE SANEAMENTO DE MINAS GERAIS - EDITAL 017/2018. FUMARC - Fundação Mariana Resende Costa 2018. Minas Gerais.

PERRONI, J.C.A, 2004. Otimização De Custos De Bombeamento De Poços Profundos Em Araraquara - Sp, São Paulo. 
